\title{
Marketing Mix Factors Influence Behavior in Inthanin Coffee Shop
}

\author{
Wiroon Toysamran and Assist Prof. Suthum Phongsamran \\ Graduate School of Business Administration Kasembundit University, Bangkok, Thailand
}

\begin{abstract}
The purpose is to study consumer behavior. To study marketing mix factors related to consumer behavior in Inthanin Coffee Shop.The study population was Inthanin coffee shop. 286 samples were selected. Using the questionnaire One-way ANOVA, t-test, Regression and Chi-square were used for data analysis. Male, age 26-30 years old. Bachelor or equivalent. Occupation And monthly income 20,001 - 30,000 baht. Importance of marketing mix factors. Overall, the mean was very high. The overall marketing promotion was moderate. Test results hypothesis Different personal factors affect the behavior of different Inthanin coffee shops. The results of ANOVA tests showed that the customers of Inthanin Coffee ShopSex, age, education, occupation and income have different effects on frequency of use in Inthanin coffee shops. Personal factors correlated with behaviors in Inthanin Coffee Shop. Chi-square test results It was found that personal factors correlated with the behavior of using the service in the Inthanin coffee shop. Effect of reliability on quality of indiniline coffee. Affect the reason for buying Intra Coffee. Affect the reason for buying Intra Coffee.

Why Buy Inthanin Coffee? Affects the person who affects the service of the Inthanin Coffee Shop.The effect of the marketing mix on the Inthanin Coffee Shop was sig. 0.0100 .0170 .018 and 0.021 respectively. The results of the regression analysis revealed that the marketing mix factors influenced the behavior of the Inthanin coffee shop.

1 quality of coffee sold in the second 2 location easy to find the 3rd place Internet Service \# 4 location of the convenience store to travel. And the modern equipment such as coffee grinder had Sig value of 0.0060 .0110 .030 0.036 and 0.039 respectively.

Suggestions from the study findings. The profession has a relation to the quality of coffee. The work of each profession may get information about different coffee can have both good and bad.

It should provide useful information about coffee to stimulate consumer demand. Age relationship is the reason for buying coffee. Because each age range is intended to buy different coffee, such as teenagers, buy coffee to consume for the body to stimulate the work. Or middle-aged people buy coffee to eat because of addiction.The study was related to persons who affected the service of Inthanin Coffee Shop. The knowledge gained from the study led to the decision to trust the person who supported the use of the Inthanin coffee shop. Age correlated with the perception of informal cafes. Because people in each age range use different media to perceive information. Most teenagers get information from electronic media. Most middlemen get information from radio and television. It should enhance the modernity of the device. Use a new coffee grinder to add the smell of coffee. Use professional staff to make snacks or snacks. Increase advertising brand reputation of Inthanin coffee shop. Make a sign of the store in easy to remember. And increase the quality of the Internet service price should adjust the price to suit the quality. It should be adjusted to suit the needs of customers. And parking should be sufficient. Marketing promotion should increase the accumulation to redeem the prize. And should have a gift to buy.
\end{abstract}

Keywords: Marketing, Factors, Inthanin

\section{Introduction}

Since most of the population is drinking coffee widely. Whether it is male or female, they all drink coffee together. Some people drink regularly in the morning to give a fresh feeling. Some people drink while driving so as not to cause drowsiness. Some people drink before work to enhance their work. Because coffee stimulates the brain and body. Athletes, or those who use it, are more likely to drink coffee to boost their energy, especially among those who labor very often. In addition, some people also drink coffee to reduce drowsiness at night. Especially in the work group at night to drink coffee regularly.

The coffee shop has a lot of coffee. Famous coffee brands such as Starbucks Black Canyon, etc. Then began a coffee shop opened in the gas station. And successful coffee shops. The coffee shop opened at the PTT gas station is a coffee shop. 
Amazon. Indan Coffee Shop is a shop that can be found at Bangchak gas station. Or by franchise in places such as universities. Therefore, the study participants were interested in studying the factors affecting the decision to use the Inthanin Coffee Shop. The result of the study is a guideline for developing the service of Inthanin coffee shop in accordance with the needs of consumers.

\subsection{Purpose of study}

1. To study consumer behavior in using Inthanin Coffee Shop.

2. To study the marketing mix factors related to consumer behavior in using Inthanin Coffee Shop.

\subsection{Assumptions of the study}

1. Different factors affect the behavior of using Inthanin Coffee Shop.

2. Personal factors correlated with behaviors of using Inthanin coffee

3. Marketing Mix Factors Influencing Behavior in Using Inthanin Coffee Shop

\section{Scope of study}

The content of marketing mix theory. And consumer behavior. Demographics and samples are available at Inthanin coffee shops in Prawet and Suan Luang districts. 286 samples were selected. The duration of study is November BE 2559 - February BE 2560.

\subsection{The benefits of the study}

1. Know the consumer behavior in using Inthanin Coffee Shop.

2. The marketing mix factors related to consumer behavior in Inthanin Coffee Shop.

3. The results of the study can be used as a guideline for the development of Inthanin Coffee.

\section{Concepts and theories of marketing mix.Marketing Mix (4P's Mix)}

1. Product. Designing a service strategy, whether in a business that produces a product or a service, must consider the customer. The needs and needs of customers that affect the product itself. The products in the service business are different from the product in terms of form and operation, so many combinations are both visible. This is not the only thing that sells to customers and the customers get the benefit and value of the product.

2. The price (cost) of the customer to waste to acquire the product, the cost here may be possible. The value of money to be paid in exchange. Cost of travel Cost of parking including time cost. The customer will compare the cost with the value of the product is worth it or not to buy it. The cost of production or service. The cost of the customer.

3. Place (s) need to consider the convenience (Convenience) of the service. Delivering to the customer the place and time of delivery, ie the customer should be as easy to reach as possible at the time and place where the customer was most comfortable.

4. Promotion means the communication of information between the seller and the customer. Contain with

4.1 Advertising is non-personal communication through media such as newspapers, radio, television, billboards.

4.2 Sales by Employee (Personal Selling) Sales by Sales Person

4.3 Promotion (Sales Promotion) is a marketing tool or activity in addition to advertising sales. Use salespeople such as making a membership card to get a discount.

4.4 Publicity and Public Relations A plan to present a good image and understanding between a business and a customer.

\section{Data Processing and Analysis}

Processed data from the questionnaire. Computer program by Percentage and Mean. Microsoft Excel, a program for pie chart and bar chart with description. The results from the chart are presented for analysis of the variables. 


\section{Statistics used in Data Analysis}

Descriptive statistics such as percentage, mean, and standard deviation to describe the demographic data of respondents and variables. Inferential Statistics are used for hypothesis testing. Identify statistics such as t-test, ANOVA, F-test (One-way ANOVA), Regression Analysis and Chi-square.

\section{Personal summary}

The respondents were 286 male and 26-30 male, respectively. Occupation And monthly income 20,001 30,000 baht.

\section{Summary of marketing mix factors.}

- Product of the study. The overall mean is very high in order of importance. There are other drinks besides coffee. Products sold in the store clean and beautiful freshness of products sold in the store. The quality of the coffee sold in the shop. Consistency of coffee and beverage flavors The taste of coffee and other beverages. A variety of coffee flavors Variety of snacks / snacks Special coffee is different from other stores. Modernization of equipment Taste of snacks / snacks The brand's reputation, the smell of coffee, the symbol of the store, easy to remember, and the internet service respectively.

- Price of the study. The overall mean is very high in order of importance. There is a clear price tag. Good price with quality. And affordable compared to other coffee shops, respectively.

- Place of the study. The overall mean is very high in order of importance. The location of the shop is close to the accommodation or office location of the convenience store. Location easy to find. Open time - close to easy to use. And parking is adequate.

- The promotion of the market (Promotion). The overall mean was moderate. Sort by: Offers through various media such as newspapers, radio, flyers, internet, the accumulation of prizes to redeem prizes. And there are some free gifts to buy.

\section{Conclusion of Behavioral Information in Inthanin Coffee Shop}

There were 286 respondents who found that their friends had a positive effect on their buying decision. Most Coffee The Inthanin Coffee Shop is the most popular information from friends. There are people who consume coffee. Most consumed in daily life. And the reliability of the quality of coffee is believed. Holds in the highest quality product.

\section{Summary of Hypothesis Testing Results 1}

Different personal factors affect the behavior of different Inthanin coffee shops. The ANOVA statistic showed that the customers of Inthanin Coffee Shop who had different gender, age, education, occupation and income had no effect on the frequency of use in Inthanin coffee shops.

\section{Summary of Hypothesis Testing Results 2}

Personal factors correlated with behaviors in Inthanin Coffee Shop. The Chi-square statistic showed that the personal factors correlated with the behavior of using the service at the Inthanin coffee shop. Affects reliability in the quality of intestinal coffee. Affects the reason for buying Inthanin coffee. Affects the person who affects the service of the Inthanin Coffee Shop. Influence of information channel on Inthanin coffee was sig. 0.010 0.017 0.018 and 0.021 respectively.

\section{Summary of hypothesis testing results 3}

Marketing Mix Factors Influence Behavior in Inthanin Coffee Shop. The results of the tests using the regression showed that the marketing mix factors influenced the behavior of using the service at the Inthanin coffee shop. The quality of the coffee sold in the second place was ranked as the third most popular restaurant. The shop is convenient to travel. And the modern equipment such as coffee grinder had Sig value of 0.0060 .011 0.0300 .036 and 0.039 respectively. 


\section{Discussion of results}

1. Different factors affect the behavior of the Inthanin Coffee Shop. The factors of sex, age, education level, occupation and income have different effects on the behavior of the service in the coffee shop. Different

2. Personal factors correlated with behavior of using Inthanin coffee service. Factors related to behavior of using Inthanin coffee shop. Is the personal factor of career. This is in line with the research conducted by Somsakul Nirandonchai (BE2554) on the behavior of choosing stand-alone coffee roasters in urban areas. In Chiang Mai, the personal factors of sex Monthly income and occupation were correlated with the selection of standalone coffee shops.

3. Personal factors were related to behaviors of using Inthanin Coffee Shop, including personal factors related to behavior of using Inthanin Coffee Shop. Is the highest personal qualification factor. This is in line with the research conducted by kanda serhjumsin (BE2555) on the behavior of accessing the Amazon coffee shop of consumers in Pathum Thani province. And highest education There was a relationship between the access to the Amazon coffee shop and those who participated in decision making.

4. Personal factors were related to behaviors of using Inthanin Coffee Shop, including personal factors related to behavior of using Inthanin Coffee Shop. What is the age factor? This is in line with the research of Nupong Bunsanong (BE2547), which studies consumer behavior of premium coffee consumers in Dusit. Bangkok's consumers are different. There are different premium coffee consumption behaviors. There are 7 brands of premium coffee. The reasons for consumption, the person influencing the decision. Consumption Popular Places The price you accept. And promotion

5. Factors related to behavior of using Inthanin coffee were personal factors related to behavior of using Inthanin Coffee Shop. What is the age factor? According to Kamolrate Lotrendrate (2007)A study on the factors affecting coffee consumption behaviors at the premium coffee shop on Silom Road among working-age consumers found that demographic characteristics of age influenced coffee consumption behaviors at coffee shops.Premium on Silom Road for working-class consumers. In terms of age, the behavior of coffee consumption at the Silom Road on the road of consumers in all age groups. Statistically significant at the .05 level.

\section{Marketing Mix Factors Influencing Behavior in Inthanin Coffee Shop}

Product quality of coffee in the shop. It is very important. Atiwat Ratanatunuong (2012) studied the consumer behavior of using fresh coffee in Thonburi. Bangkok has found that the products are very important in terms of quality. The reputation of the brand and the quality of the coffee sold in the shop. Modern equipment such as coffee grinder. It is very important. According to research by Kintha Chuniyom (BE2547), the decision to choose a coffee roaster for the consumers found that the respondents would focus on cooked coffee. From the freshest seeds to the next, there will be modern cooking tools and a selection of roasted coffee. Famous coffee houses are well known. There are clear and distinct coffee mugs displayed by consumers. There is a minimum opinion on the issue of coffee mugs according to their size. And Internet Services It is very important. This is in line with Piyapan Pverangsawad BE2553 research.) The consumer behavior of using coffee shops in Muang Lampang province showed that the importance factors were the high level, the cleanliness of the shop and the shop area. Having a comfortable order Atmosphere in the restaurant is friendly. Cleanliness of the bathroom Decoration and arrangement of tables, chairs and equipment is organized. The smell of coffee in the shop. The sign of the beautiful shop visible. Air conditioning Modernization of equipment Like coffee machine Internet service Newspapers, magazines, customer service. And there is space for smoking.

Place (Place) And convenient to travel. It is very important. According to research by Somsakul Nirandonchai (BE2554), the behavior of choosing stand-alone coffee shop in Bangkok metropolitan area. Chiang Mai found that the place featured a high level of respect. The suitability of the location. And the ease of travel.

\section{Suggestions from the study}

1. The profession is related to the reliability of the quality of coffee. The work of each profession may get information about different coffee can have both good and bad. Should provide good information of coffee to stimulate consumer demand. 
2. Age is related to the reason for buying coffee. Because each age range is intended to buy different coffee, such as teenagers, buy coffee to consume for the body to stimulate the work. Or middle-aged people buy coffee to eat because of addiction.

3. The study was related to persons who affected the service of Inthanin Coffee Shop. The knowledge gained from the study led to the decision to trust the person who supported the use of the Inthanin coffee shop.

4. Age related to perception of information about Inthanin Coffee Shop People in each age range use different media to perceive information, such as most teens who receive information from electronic media. Most middle-aged people get information from radio and television.

5. Products It should enhance the modernity of the device. Use a new coffee grinder to add the smell of coffee. Use professional staff to make snacks or snacks. Increase advertising brand reputation of Inthanin coffee shop. Make a sign of the store in easy to remember. And increase the quality of Internet services.

6. Price should be adjusted to suit the quality. And not expensive compared to other stores.

7. The place should adjust the turn-on time to suit the needs of customers. And parking should be sufficient.

8. Promotion Should increase the accumulation to redeem the prize. And should have a gift to buy.

\section{Suggestions for the Next Study}

1. The questionnaire should contain clear questions. There should be no similar question. To reduce the number of queries. If the number of questionnaires is large, the respondents will not be able to cooperate enough.

2. Insufficient data collection time Should focus on the storage of information.

\section{Referencing and Biography}

[1] Kamolrate rojrangrate (BE.2550) Factors Affecting Coffee Consumption Behaviors at Premium Coffee Shop on Silom Road. Master of Business Administration Srinakharinwirot University.

[2] Konpach juntonjarang (BE.2554) The study of purchasing behavior and marketing mix factors of instant coffee. In the district. Khon Kaen. Independent Study Report, MBA Marketing Faculty of Management Science Khonkaen University.

[3] Kanda surjamsin (BE.2555) Accessibility of Amazon Coffee Shop of consumers in Pathum Thani Province. Independent Study, MBA Major Marketing Rajamangala University of Technology Thanyaburi

[4] Chatyapong samerjai (BE.2548). Service marketing and management. Bangkok: SE-EDUCATION.

[5] Parinya chatchom (BE2554). Decision MakingOnline:http://www.novabizz.com/NovaAce/Behavior/Decision_Making.htm

[6] Nuoung bunsanong (BE2547) Consumer behavior of premium coffee consumers in Dusit Bangkok. Graduate School. Rajabhat Institute Suan Dusit.

[7] Cnitha chuniyom (BE.2547) Factors in decision making of roasted coffee. Graduate School. Rajabhat Institute Suan Dusit.

[8] Nitikang tarangretmarai (2554) Marketing factors related to consumption behavior of fresh coffee of consumers in Bangrak, Bangkok. Independent Study, MBA Sukhothai Thammathirat Open University

[9] Kotler, Philip. (1999) Marketing Management: An Asian Perspective. $2^{\text {nd }}$ ed. New Jersey: Prentice Hall International. 